\title{
Distribusi Kerang Geloina sp. (Bivalvia: Corbiculidae) di Kawasan Mangrove Segara Anakan, Cilacap
}

\author{
Chrisna Adhi Suryono \\ Jurusan IImu Kelautan, Fakultas Perikanan dan IImu Kelautan, Universitas Diponegoro \\ JI. Prof. Soedarto, SH. Kampus UNDIP Tembalang, Semarang 50275 \\ Email : chrisna_as@yahoo.com
}

\begin{abstract}
Abstrak
Segaraanakan merupakan salah satu estuaria terbesar di Pulau Jawa yang terkenal dengan keanekaragaman hayatinya. Diantara biota yang terdapat adalah kerang totok (Geloina sp) yang berasosiasi dengan hutan mangrove. Karena memiliki nilai ekonomis maka selalu di tangkap. Maka dari itu sangat tepat jika kerang tersebut dipelajari ekologis maupun biologisnya. Tujuan dari penelitian ini adalah untuk mengetahui distribusi dan stuktur populasi kerang Geloina sp tersebut. Penelitian dilakukan di Segaraakan Cilacap pada empat stasiun yang berbeda salinitasnya $(13,15,30$ dan $32 \mathrm{ppt})$. Sifat penelitian adalah studi kasus, metoda pengambilan sampel yang digunakan adalah metoda sampling area. Data yang diambil meliputi kerang dan kondisi perairan. Data yang didapatkan dikelompokan berdasarkan kelas ukuran panjang cangkang selanjutnya dilakukan uji chi kwadrat untuk menentukan pola sebaran. Hasil penelitian menunjukan kerang yang didapat adalah $G$. erosa dengan pola sebaran merata pada keempat stasiun penelitian yang berbeda salinitasnya. Adapun kepas ukuran kerang yang didapat dalam keempat stasiun dapat dikelompokan menjadi kelas ukuran $<3,3-3,9,4-4,9,5-5,9,6-6,9,7-7,9, .>8 \mathrm{~cm}$. Populasi kerang terbanyak pada semua stasiun adalah kelas ukuran $6-6,9 \mathrm{~cm}$
\end{abstract}

Kata Kunci : Segaraanakan, Geloina sp, salinitas

\begin{abstract}
Abstrack
Segeraanakan is the widest estuaries in Java Island and the famous high diversity. One of fauna found which associate with the mangroves was totok mussel Geloina sp. That mussel had economic value so that faced high exploited along season. Considering that condition a study of distribution and their population structure was very importance. The research was carried out on Segaraanakan Cilacap on different station which had different salinity $(13,15,30$ and $32 \mathrm{ppt})$. The case study type research and sampling area method was used to collect the data of information of the Geloina sp. The data collected in the field was mussel population and water quality condition where the mussel life. The data of mussel was grouping in several length of class and following chi quadrant test to define the distribution of Geloina sp. The result of the study showed, Thad the Geloina sp was uniform distribute along the fourth station which had different salinity and the length of class mussel was found $<3,3-$ $3,9,4-4,9,5-5,9,6-6,9,7-7,9, .>8 \mathrm{~cm}$. The class length of $6-6,9 \mathrm{~cm}$ was the highs number of mussel class on forth station in Segaraanakan
\end{abstract}

Keywords : Segaraanakan, Geloina sp, salinity

\section{PENDAHULUAN}

Ekosistem mangrove di Laguna Segaraanakan dicirikan dengan tingginya keanekaragaman fauna yang berasosiasi diantaranya seperti kelompok kerang kerangan dari famili Corbiculidae yang berasosiasi dengan mangrove seperti Geloina erosa, Geloina expansa dan Geloina bengales (Morton, 1984). Lebih 
khusus lagi kerang jenis tersebut hanya terdadap didaerah yang berhutan mangrove. Di Segara Anakan Cilacap kerang totok (Geloina sp) jumlahnya sangat melimpah dan dimanfatkan oleh penduduk setempat untuk dikonsumsi dan dijual. Mereka mengambil kerang tersebut secara tidak teratur baik jumlah, ukuran kerang dan waktunya sehingga kemungkinan besar nantinya akan berpengaruh terhadap populasi kerang.

Namun Segaraanakan merupakan estyaria yang dialiri beberapa sungai besar seperti Sungai Donan, Sungai Jeruk Legi, Sungai Cikonde, Sungai Cibereum dan Sunagi Citandui. Banyaknya masukan air dari sungai tentunya memberi dampak yang luas pada estuaria dan biota yang ada didalamya termasuk Geloina sp karena disamping membawa sedimentasi yang tinggi aliran tersebut juga menyebabkan fluktuasi salinitas yang tinggi. Namun G.erosa merupakan kerang yang hidup di daerah berlumpur, diantara daun daun yang telah membusuk, dan di kolam yang terbentuk diantara daun daun mangrove (Morton dan Morton, 1983). Frogila (1989) menyatakan bahwa sediment merupakan habitat yang cocok bagi kerang dari Famili Corbiculidae. Lebih lanjut Morton (1984) menyebutkan bahwa Geloina sp distribusinya meliputi hutan mangrove di Hongkong, Malaisia, Singapura, Thailand, China, Jepang, Australia, Vietnam, Burma, India dan
Philipina. Hal demikian yang menyebabkan mengapa Geloina mampu hidup dan berdistribusi sangat luas di Segaraanakan. Maka dari itu penelitian struktur populasi dan dsitribusi kerang Geloina sp di Laguna Segaraanakan sangat penting dilakukan karena dilaguna tersebut perubahan salinas antara laut (tinggi) dan tawar (rendah) sangat drastis.

\section{MATERI DAN METODE}

Lokasi penelitian di lakukan di daerah Ujung Alang Segara Anakan Cilacap. Materi yang diteliti adalah kerang Geloina sp yang terdapat dilokasi tersebut. Sampel diambil pada daerah bersalinitas rendah ke salinitas tinggi atau lebih tepatnya dari arah Sungai Bugel menuju ke estuary (laguna) Segara Anakan. Sampel diambil di empat stasiun dengan salinitas rendah sampai tinggi tergantung salinitas setempat.

Pengambilan sampel dilakukabn dengan transek seluas $100 \mathrm{~m}^{2}$ dan penghitungan sampel dilakukan dengan quadrant $1 \mathrm{~m}^{2}$ dan diambil pada 10 titik yang berbeda dan diulang 3 kali pada waktu berbeda. Penentuan letak quadran pada areal transek seluas $100 \mathrm{~m}^{2}$ terlebih dahulu ditentukan diatas kertas sebelum terjun mengambil sampel hal ini dilakukan untuk menghindari human bias akibat subjektifitas peneliti.

$10 \mathrm{~m}$

Keterrangan :

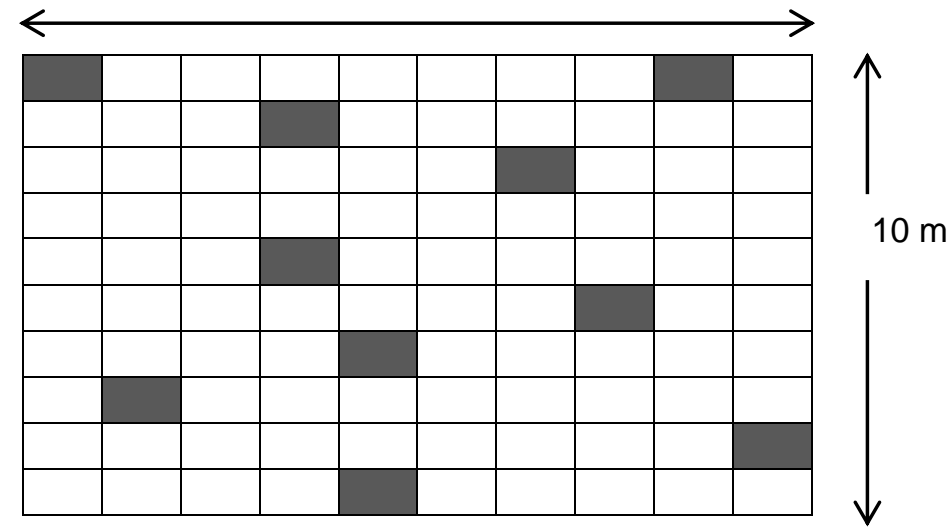

: Letak Quadrant 1 × $1 \mathrm{~m}$

Gambar 1. Letak quadrant dalam areal transek di kawasan hutan mangrove Segara Anakan Cilacap. 
Data yang diperoleh dari keempat stasiun yang berbeda salinitas $(13,15,30$ dan 32 ppt) berupa kerang totok yang berbeda ukuran ditabulasikan. Untuk mengetahui struktur populasi kerang totok pada masing masing stasiun dilihat dari struktur ukuran kerang dilakukan dengan uji indek dispersiaon (Sokal dan Rohlf, 1995) dengan rumus sebagai berikut :

$$
\mathrm{dl}=\mathrm{S}^{2} / \mu
$$

dimana :

$S^{2}=$ Ragam banyaknya individu

$\mu=$ Rata rata kepadatan populasi yang diduga (individu/meter)

Pola sebaran ditentukan dengan kriteria:

Pola sebaran acak, jika $S^{2}=\mu$

Pola seberan mengelompok jika $S^{2}>\mu$ Pola sebaran seragam/ merata, jika $S^{2}<\mu$
Selanjutnya untuk mengetahui frekuensi kehadiran (Fr) yang menunjukkan prosesntase kehadiran tiap jenis dalam suatu kuadrat pengamatan digunakan perhitungan :

$$
F r=\frac{n i}{n} x 100 \%
$$

dimana :

$\mathrm{Fr}=$ Frekuensi kehadiran

$\mathrm{ni}=$ Jumlah kuadrat jenis i ditemukan

$\mathrm{n}=$ Jumlah seluruh kwadrat pengamatan

\section{HASIL DAN PEMBAHASAN}

Hasil pengamatan struktur populasi kerang Geloina sp di Segara Anakan Cilacap tersusun atas kelompok kerang berukuran $<3,3-3,9,4-4,9,5-5,9,6-6,9$, $7-7,9,>8 \mathrm{~cm}$. Kerang tersebut

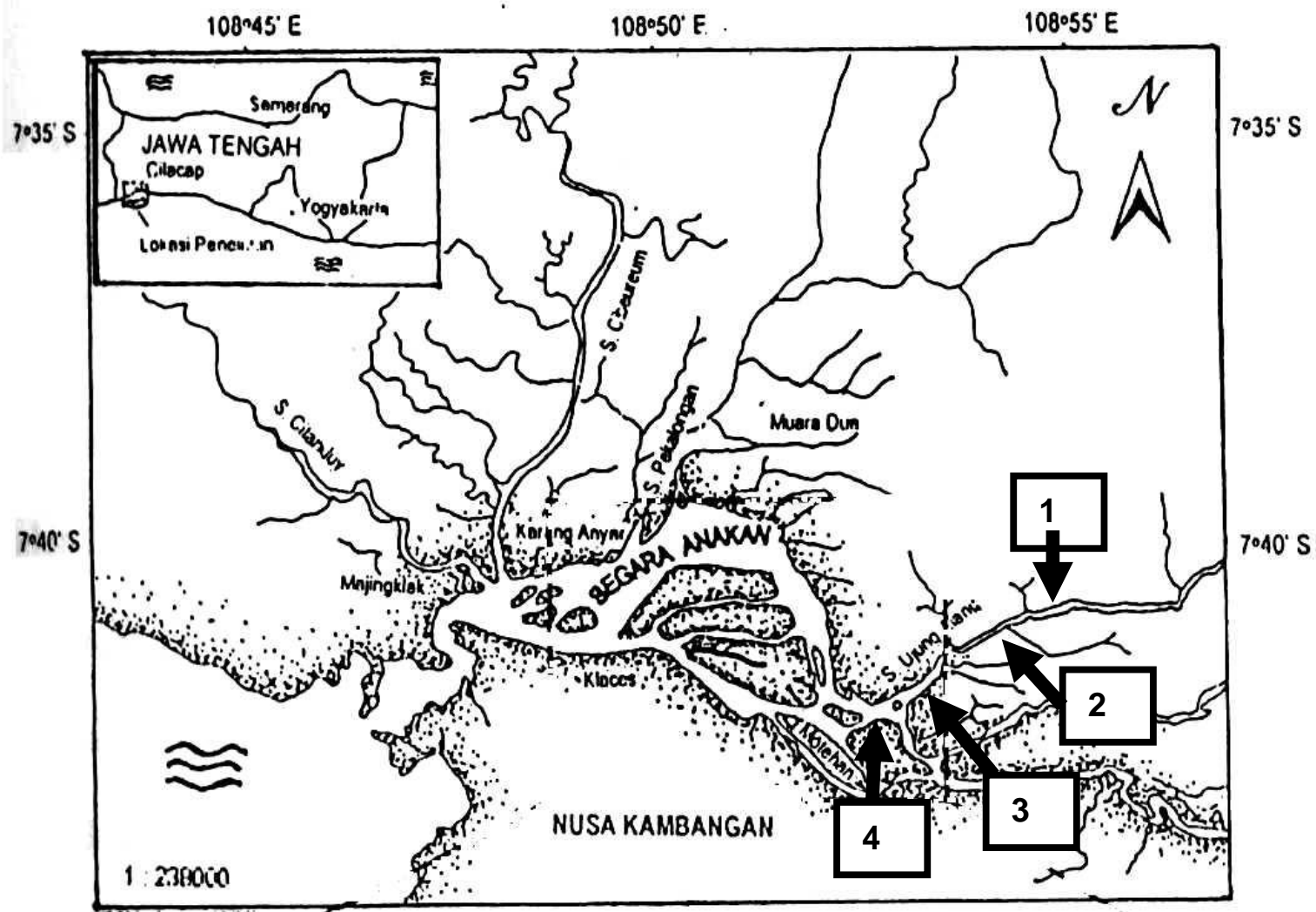

Keterangan :

: Lokasi stasiun

Gambar 2. Peta loakasi penelitian dan titik sampling 


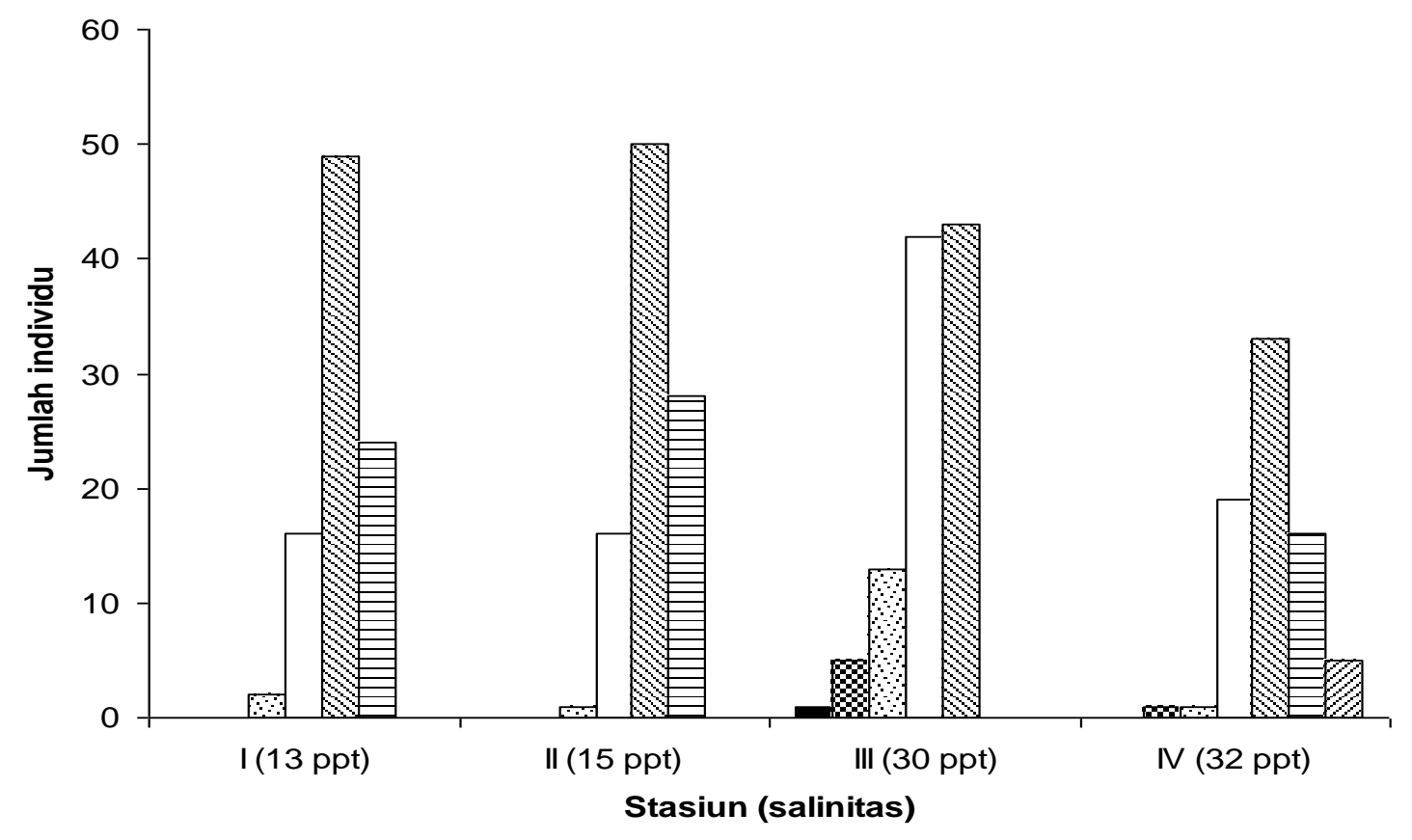

口 $<3 \quad 3-3,9 \square 4-4,9 \square 5-5,9 \backsim 6-6,9 \quad \boxminus 7-7,9 \square>8$

Gambar 3. Kepadatan dan sebaran Geloina sp pada stasiun yang berbeda dan kelas ukuran $(\mathrm{cm})$ berbeda

didapatkan pada stasiun I sampai IV dengan kisaran salinitas antara $13-32 \mathrm{ppt}$ untuk lebih jelasnya dapat dilihat pada Gambar 3. Jumlah kerang terbesar didapatkan pada stasiun III yang salinitas airnya 30 ppt sedangkan stasiun lainnya relative hamper sama jumlah geloina yang didapatkannya. Bila di lihat dari kelas ukuran yang ada, populasi tertinggi didapatkan pada kelas ukuran $6-6,9 \mathrm{~cm}$ dan yang paling rendah pada kelas ukuran $<3$ dan $>8 \mathrm{~cm}$. Hal tersebut juga dibuktikan dengan uji $t$ dimana $\dagger$ hitung $=-1,086735$ yang mengindikasikan tidak ada perbedan jumlah/kepadatan kerang antar stasiun.

Hasil analisa data kepadan kerang Geloina didapatkan bahwa nilai indeks penyebaran (dl) kerang pada masing masing stasiun. Nilai indek (dl) pada masing masing stasiun I, II, III dan IV adalah sebagai berikut 0,7065, 0,5056, 0,1699 dan 0,0606 . Karena nilai indeks (dl) $<1$, maka pola sebaran kerang totok untuk semua stasiun merata hal tersebut juga terlihat pada uju Chi Kuadrat. Sedangkan hasil pengamatan kondisi lingkungan perairan masing masing stasiun penelitian menunjukakan bahwa temperatur air relative konstan antara $28-29 \circ \mathrm{C}$, salinitas terdapat degradasi atau penurunan dari stasiun IV menuju stasiun I bewrvariasi antara 32 - 13 ppt. Sedangkan subtract dasar dimana geloina hidup adalah Lumpur berpasir untuk semua stasiun pengamatan. Bahan organik yang terdapat pada subtract dasar juga tidak adanya perbedaan yang menyolok berkisar antara $14,90-16,44 \%$, sedangkan vegetasi yang dominant yang terdapat dalam stasiun pengamatan adalah Derris heterophilla, Achantus illicifolius, Bruguera sp.

Penyebaran kerang totok (G. erosa) di Segara Anakan terlihat merata baik pada daerah yang bersalinitas rendah maupun tinggi. Hal tersebut sesuai dengan Odum (1993) yang menyatakan bahwa penyebaran merata datap terjadi jika persaingan antar individu sangat keras yang mendorong pembegian ruang hamper sama. Kennish (1990) mengatakan bahhwa keanekaragaman di daerah estuaria biasanya rendah tetapi kepadatan organismennya yang ada bias sangat tinggi. Kepadatan organisme yang tinggi baik antara spesies maupun sesama 
spesies itu sendiri menyebabkan adanya persaingan untuk mendapatkan ruang guna memeperoleh makanan, tempat berlindung dari predator dan tempat untuk berkembang biak. Dengan demikian $G$. erosa sebagai organisme bentik harus bersaing dengan organisme bentik lainnya yang hidup di daerah mangrove seperti dari golongan Polychaetha dan Crustacea (Kennish, 1990). Barnes dan Hughes (1988) menjelaskan bahwa predasi bukan merupakan salah satu factor yang mengontrol kepadatan organisme bentik tetapi kepadatan organisme mentik lebih banyak dipengaruhi oleh kompetisi. Lebih lanjut Barnes dan Hughes (1988) menjelaskan bahwa kompetisi merupakan factor untuk mempertahankan ekspansi yang terbatas, meskipun factor fisik dan biologis dalam lingkungan dketahui berpengaruh langsung dan dapat menyebabkan berkurangnya jumlah individu dalam populasi. Jlka melihat kondisi lingkungan selama penelitian pada ke empat stasiun pengamatan yang berbeda salinitasnya menunjukan variasi suhu, salinitas, bahan organic mauppun vegetasi hampir sama sehingga dapat dikatakan bahwa perbedaan struktur populasi yang terlihat dari jumlah ukuran yang berbeda diduka karena factor salinitas.

Dari data yang ada pada hasil penelitian menunjukan bahwa pada daerah yang bersalinitas tinggi pada stasiun III dan IV rata rata kepadatannya lebih rendah bila dibandingkan pada daerah yang bersalinitas lebih rendah pada stasiun I dan II. Penurunan jumlah individu pada daerah bersalinitas tinggi diperkirakan karena pengaruh pengambilan oleh nelayan karena bila dilihat dari kondisi lingkungan dapat dikatakan relative sama. Dijumpainya $G$. erosa dengan ukuran panjang cangkang yang lebih bervariasi pada stasiun III dan IV (daerah yang bersalinitas tinggi) diduga pada daerah tersebut terdapat spat dan kerang dari berbagai ukuran, karena pada daerah yang bersalinitas lebih tinggi spat banyak hidup di daerah tersebut. Hartati dan Suryono (2000) menyebutkan bahwa bivalvia dari golongan tiram yang menempel pada subtrat di estuaria Mlonggo Jepara mencapai puncaknya pada akhir musim hujan yang salinitasnya mulai naik.

Hal tersebut juga terlihat di Segara Anakan untuk kerang $G$. erosa dimana pada daerah yang salinitasnya tinggi terdapat banyak variasi kelas ukuran kerang. Bayne (1976) menginformasikan bahwa kerang yang hidup di daerah empat musim tumbuh dengan cepat pada musim semi dan panas dimana suhu dan salitas perairan meningkat dmikian juga terhadapt $G$. erosa yang yang hidup di Segar Anakan pada salinitas tinggi dan lebih tinggi akan memiliki ukuran dan variasi ukuran lebih bsar hal ini membuktikan bahwa pada daerah yang bersalinitas tinggi cocok untuk hidup

Tabel 1. Kondisi linkungan masing masing stasiun penelitian

\begin{tabular}{ccclll}
\hline Stasiun & Suhu $\left({ }^{\circ} \mathrm{C}\right)$ & Salinitas (ppt) & Subtrat & $\begin{array}{l}\text { Bahan } \\
\text { Organik }\end{array}$ & \multicolumn{1}{c}{ Vegetasi } \\
\hline Stasiun I & 29 & 13 & $\begin{array}{l}\text { Lumpur } \\
\text { berpasir }\end{array}$ & 16,15 & $\begin{array}{l}\text { Derris heterophilla } \\
\text { Achantus illicifolius } \\
\text { Bruguera sp } \\
\text { D. heterophilla }\end{array}$ \\
Stasiun II & 29 & 15 & $\begin{array}{l}\text { Lumpur } \\
\text { berpasir }\end{array}$ & 16,44 & $\begin{array}{l}\text { A. illicifolius } \\
\text { Bruguera sp } \\
\text { D. heterophilla }\end{array}$ \\
Stasiun III & 28 & 30 & $\begin{array}{l}\text { Lumpur } \\
\text { berpasir }\end{array}$ & 15,27 & $\begin{array}{l}\text { A. illicifolius } \\
\text { Bruguera sp } \\
\text { D. heterophilla } \\
\text { A. illicifolius } \\
\text { Bruguera sp }\end{array}$ \\
\hline
\end{tabular}


G. verosa hal tersebut terlihat dari ukuran variasi ukuran yang lebih besar dari pada daerah yang bersalinitas rendah. Tidak dijunpainya $G$. erosa dengan ukuran lebih kecil dari $2 \mathrm{~cm}$ di daerah penelitian mengindikasikan bahwa dimungkinkan individu muda kerang ini masih berada di bagian lain di hutan mangrove tersebut. Morton (1984) menyebutkan bahwa hal yang menarik dari struktur populasi $G$. erosa dan $G$. expansa adalah bahwa kedua spesies ini relative jarang ditemukan pada stadium mudanya dengan ukuran cangkang yang masih kecil.

Banyaknya Geloina ditemukan didaerah mangrove dari pada jenis bivalvia lain diduga hanya jenis Geloina yang mampu beradaptasi pada daerah mangrove karena tingginya fluktuasi salinitas demikian juga lokoasi penelitian Segara Anakan. Berdasarkan kondisi umum daerah pengamatan diatas dapat diketahui bahwa daerah tersebut memang cocok untuk kehidupan G. erosa. Morton (1976) mengatakan bahwa kawasan hutan mangrove Asia Tenggara ditemukanan berbagai macam jenis bivalvia dimana $G$. erosa merupakan salah satu organisme yang tersebar luas dan biasanya ditemukan sepanjang sisi daratan hutan mangrove maupun didalam hutan mangrove itu sendiri.

Habitat ditemukannya hutan $G$. erosa ini hanya tergenang saat terjadi pasang tinggi dan terjadinya banjir meskipun G. erosa dapat hidup pada daerah yang terekspos dalam waktu yang lama (Morto, 1976). Subtrat di daerah penelitian di semua stasiun sebagian besar adalah lumpur berpasir. Demikian pula pada $G$. erosa di Singapura diketahui subtrarnya dasarnya adalah pasir kwarsa. Dapat dimengerti bahwa habitat kerang tersebut adalah pasir yang mengandung lumpur seperti yang ada di Segara Anakan maupun tempat tempat lain.

\section{KESIMPULAN}

Berdasarkan hasil penelitian dapat disimpulkan bahwa $G$. erosa yang terdapat di Segara Anakan tersusun atas kelompok populasi dengan kelas ukuran atas kelompok kerang berukuran $<3,3-3,9,4-$ $4,9,5-5,9,6-6,9,7-7,9, .>8 \mathrm{~cm}$. Distribusi tersebar merata di hutan mangrove.

\section{DAFTAR PUSTAKA}

Barnes, R. D and Hoghes, 1988. An introduction to marine ecology. Sounders College Publishing. USA. $351 \mathrm{p}$

Bayne, B.L. 1976. Marine mussels: Their ecology and physiology. Cambridge University Press. Cambridge. $351 \mathrm{p}$

Frogila, C. 1989. Clam fisheries with hydroulic dredges in the Adriatic sea. Marine invertebrate fisheries. Edited by F. Caddy. John Willey \& Sons Inc. USA 507 - 524 pp.

Hartati, R dan Suryono. C.A. 2000. Oyster spatfall in Mlonggo Waters Jepara, Indonesia. Phuket marine Biology Center. Special Publication, 21 (1): 183 - $186 \mathrm{pp}$.

Kennish, 1990. Ecology of estuaries. Vol 2: Biological aspects. CRC Press. New Jersey. USA. $391 \mathrm{p}$.

Morton, B and Morton, J. 1983. The sea shore ecology of Hongkong. Hongkong University Press. 77 - 86 pp.

Morton, B. 1976. The biology and functional of The Southeast Asian Mangrove Bivalve, Polymesoda Gelonia erosa (Solander, 1976), (Bivalve: Corbiculidae). Can. J. Zool. 54: 482 500.

Morton, B. 1984. A review of Polymesoda (Gelonia) Gray, 1842 (Bivalve: Corbiculidae) from Indo Pacific mangrove. Asian Marine Biology, 1: 77 $-86$.

Odum, E. P. 1993. Fundamental of ecology. W.B. Sounders Compapy. Philadelphia. $697 \mathrm{p}$.

Sokal, R. R and Rohlf, F. J. 1995. Biometry : The principles and practice of statics in biological research. W. H. Freemen and Company. New York. 887 p.

Zar, J. E. 1996. Biostatistical analysis. Prentice Hall, New Jaersey. 662 p.Golley. 1962. The stucture and metabolism of a Puerto Rican Red mangrove forest in Malay. Ecology, 43: 9 - 10. 